Sarah Polborn

The Political Economy of Carbon Securities and Environmental Policy

Department of Economics 


\title{
The Political Economy of Carbon Securities and Environmental Policy
}

\author{
Sarah Polborn*
}

September 7, 2010

\begin{abstract}
The costs of the current suboptimal carbon abatement policy are likely in the range of 3 to 6 trillion 2005 US dollars. Using methods from the political economy of environmental policy, the paper develops a new carbon abatement policy instrument, carbon securities. A carbon security entitles its owner to a fixed proportion of ex ante unknown total emissions. This creates an additional group of stakeholders on the side of the issue that has traditionally been underrepresented. The advantages over existing systems include an equilibrium carbon price closer to the social optimum, a more predictable environmental policy, and higher investment in abatement technology.
\end{abstract}

JEL: D72, Q54, Q58

Keywords: Carbon abatement, environmental policy, global warming, interest groups, lobbying, policy instrument design, political process.

*Polborn: Department of Economics, Aarhus School of Business, Frichshuset, Hermodsvej 22, DK-8230 Aabyhoj, Denmark, SarahP@asb.dk. I would like to thank Barry Ickes, Mark Roberts, Vijay Krishna, Mattias Polborn and seminar participants at Illinois, Penn State, Aarhus School of Business and Copenhagen School of Business for helpful comments and discussions. Financial support from the National Science Foundation under Grant SES-0624354 is gratefully acknowledged. Comments welcome. 
There is strong scientific evidence that to maximize the present value of world income a reduction of carbon dioxide emissions by at least 10 percent is advisable. The currently implemented emission reductions of a few percent fall short of this benchmark. The costs of this suboptimal policy choice are likely in the range of 3 to 6 trillion 2005 US dollars and possibly higher (Nordhaus (2010), Keller et al. (2007)). There is strong evidence that industry interests are at least in part responsible for the failure of governments to pass appropriate climate legislation. A recent example is the US climate change bill that was eventually rejected in the Senate in 2010. As a whole the US economy would most likely not be significantly hurt by moderate carbon abatement, but certain industries - in particular oil and coal - would be. It is not surprising that these industries mounted a large lobbying campaign to protect their interests. ${ }^{1}$

Carbon abetment policy all over the world is influenced by lobbyists. While there are some environmental interest groups, there are better financed, more influential lobbies representing the interests of industries that feel that they benefit from a low level of carbon abatement. The outcome is frequently the implementation of a policy that deviates from the social welfare maximizing policy and makes concessions to interest groups (Markussen and Svendsen (2005), Ekins and Speck (1999)).

The existing literature on the political economy of environmental policy identifies lobbies as likely contributors to suboptimal policy choices. This paper takes the analysis one important step further by suggesting a new policy instrument, carbon securities, that perform better in a political environment with lobbying than existing policy instruments. The main advantage of the policy instrument I propose is that it creates stakeholders with an interest in low carbon emissions. The active participation of this group in the policy-making process counterbalances to an extend the lobbying of industries that feel that they benefit from a low level of carbon abatement, in the following referred to as the carbon-using industry.

Specifically, suppose a total of $n$ carbon securities is sold at time $t=1$. A carbon security gives the owner of the security the right to emit (or to sell this right) at time $\mathrm{t}=2$ up to $\frac{1}{n} \mathrm{X}$, where $\mathrm{X}$ is the society's total desired carbon emissions for period 2. The amount $X$ is unknown to any potential buyer of the security at the time when she has to decide whether she wants to purchase a security or not. At the beginning of period 2, the political process determines the society's total desired

\footnotetext{
${ }^{1}$ Between January 2009 and and June 2010 firms from the U.S. oil and gas sector spent $\$ 250$ million on lobbying. Spending in 2009 was up by $30 \%$ increase compared to 2008. Lobbying expenditures of the coal industry increased in 2008 and have since been at significantly higher levels than in 2007 and before. (Source: Center for Responsive Politics).
} 
carbon emissions, $\mathrm{X}$. When choosing $\mathrm{X}$ the political process takes into account the voters' preferences and any contributions from lobbies representing either the interests of the carbon-using industry or the owners of carbon securities. ${ }^{2}$

While both emission permits and carbon securities establish property rights, there are some important differences. Permits give the owner the right to emit a fixed amount of carbon which is set prior to the sale of the permit. Carbon securities entitle the owner to a fixed proportion of total emissions, which have not yet been set at the time when the securities are sold. The government can at any time print additional permits after the initial sale, while it cannot print additional securities until the current securities have matured. Alternatively, it is possible to think of a carbon security as a bond that pays a coupon in the form of a carbon allowance of $\frac{1}{n} X$.

The paper considers a two-period model of an economy using carbon securities. The key results of the two-period model extend in a straight forward manner to a multi-period framework in which a security is valid until period $\mathrm{T}$ and gives the owner the right to emit a fixed proportion of total desired emissions each period between 2 and T. ${ }^{3}$ Therefore the paper focusses on the more tractable two-period model.

The paper in a sense bridges the gap between the literature on the political economy of environmental policy (see for example Stavins (2004), Oates and Portney (2003), Aidt (1998)) and the literature on environmental policy instrument design (see for example Baumol and Oates (1988), Keohane et al. (2002), Metcalf (2009), Murray et al. (2009), Webster et al. (2010)).

As in Grossman and Helpman (1994), this paper assumes that the government's decision making is not only influenced by social welfare considerations but also by lobbies who make campaign contributions if they think that attempting to influence the carbon price is in their best interest. For example, under a carbon tax system the carbon-using industry has an incentive to lobby for a low tax rate. Under a carbon securities system, the lobby of the carbon-using industry is in favor of a large emission total, $X$, while the owners of the securities have an incentive to organize and lobby in favor of an emission quantity that maximizes

\footnotetext{
${ }^{2}$ The term 'carbon-using industry' is used to refer to all industries which would be subject to a carbon tax or a carbon permit system. For example, the Waxman-Markey proposal applies to about 85 percent of firms.

${ }^{3}$ A related yet significantly different policy tool are long term permits as proposed by McKibbin and Wilcoxen (2002). However, their long-term permit entitles the owner to emit a specified amount of carbon every year for the life of the permit. To the best of my knowledge no permit system with long term permits with ex ante uncertain yearly emission allowance has been suggested.
} 
the value of the securities.

The paper shows that carbon securities have a number of advantages over existing policy tools. First, the lobbying process leads to a carbon price level that is closer to the social optimum than with a tax or permit system. This is a direct consequence of the presence of stakeholders with an interest in low carbon emissions. Second, climate and political uncertainty have a smaller effect on the expected variance in the carbon price. While there is ex ante uncertainty about the amount of carbon emissions allowed per security, the variance of the carbon price is smaller. Third, there is higher investment in carbon abatement technology with carbon securities. There is a stronger incentives to develop and adopt abatement technology since carbon securities encourage both a higher and a more stable carbon price. Fourth, a system based on carbon securities also has implications for commitment to environmental policy. The introduction of carbon securities alters the policy environment so that the government can, in effect, credibly commit to long term policies even when the government can only commit to property rights but not to tax rates or policy levels. When a government introduces a carbon tax, the next government can fairly easily discontinue the carbon tax. The property rights established when carbon securities are introduced are significantly more stable.

\section{The Model}

Both policy instruments considered here - carbon tax and carbon securities - are studied within two period games, referred to as tax game and the carbon securities game. At the beginning of the first period, the government announces the policy instrument of its choice. If carbon securities are the chosen policy instrument, the government sells the securities. The potential buyers are the $m$ carbon-using firms and investors that do not belong to the carbon-using industry. Each carbon-using firm $i$ chooses its level of investment in abatement technology $I_{i}$. The carbonusing industry and the owners of carbon securities each organize themselves as a lobby. In the second period, information about the state of the world is revealed. The lobby or lobbies then offer their contribution schedule(s) which are conditional on the carbon price selected. The government chooses the level of the carbon price that maximizes its welfare. Then each owner of a carbon security sells her carbon allowance, $\frac{1}{n} X$, to firms required to hold a carbon allowances equal to their carbon emission in period 2. The following describes the stages of the game in more detail starting with the last stage. 
Consider period 2 of the carbon securities game. Let periods be short so that demand for energy, $D$, can reasonably be approximated as deterministic. Then setting an emission level $X$ and setting a carbon price are equivalent. For each level of aggregate investment in energy-saving technology, $X$ determines the carbon price via

$$
D(p, I)=X
$$

where $D$ is a decreasing function of both the carbon price $p$ and aggregate investment in energy saving technology $I$. Alternatively, in the tax game the government sets the price of carbon $p$ directly. For ease of comparison between the tax game and the carbon securities game and also to stay within the established convention of the literature based on Grossman and Helpman (1994), the government's choice variable is the carbon price in both games.

Social welfare depends on the amount of carbon emissions. On the one hand, high emissions lead to more global warming and hence higher global warming related costs $G_{W}$. These cost are a decreasing function of $p, \partial G_{W} / \partial p<0$, and also a decreasing function of $I, \partial G_{W} / \partial I<0$. On the other hand, a high carbon price has adverse effects on social welfare since it has negative effects on the carbon-using industry and leads to higher consumer prices. Social welfare is here to be thought of as discounted GDP. This consumption cost, $G_{C}$, increases with $p$, $\partial G_{C} / \partial p>0$, but decreases with $I, \partial G_{C} / \partial I<0$. The social cost of the carbon price is defined as

$$
G(p, I)=G_{W}(p, I)+G_{C}(p, I)
$$

$G(\cdot)$ is the difference between the expected cost of global warming which decrease with emissions, $X$, and the benefits of a low energy price. In practice, there is considerable uncertainty about $G$. So $G$ is to be interpreted as a best estimate.

The government welfare is the weighted sum of campaign contributions and voters' welfare:

$$
W_{G}(p, \theta, I)=C_{B}(p, \theta, I)+C_{E}(p, \theta, I)-\theta G(p, I)
$$

$C_{B}$ and $C_{E}$ are the campaign contributions of the carbon securities holders and the carbon-using industry, respectively. The government chooses $p$ to maximize $W_{G}$. The variable, $\theta$, can be understood as the government's preference variable. In the Grossman Helpman model it is interpreted as the weight of voter welfare relative to campaign contributions. A politician with a high value of $\theta$ values the interests of the electorate more highly than a politician with a low value of $\theta$. The parameter $\theta$ is interpreted as climate or political uncertainty as Section 
II.B elaborate. Note that in period 1 , when the investment decision is made, $\theta$ is unknown. At the beginning of the second period, $\theta$ is realized.

Next, consider the lobbying stage of the game. It is assumed that the firms of the carbon-using industry are able to organize themselves into a lobby group in order to influence the political process and that the lobby of the carbon-using industry does not face any borrowing constraints when it makes campaign contributions.

The gross of contributions welfare of the carbon-using industry is

$$
W_{E}=\sum_{i=1}^{m}\left(\pi_{i}\left(I_{i}, p\right)-I_{i}\right)
$$

where $p$ is the carbon price and $\pi_{i}$ is the profit of firm $i . \Pi=\sum_{i=1}^{m}\left(\pi_{i}\left(I_{i} ; p\right)\right.$ is the total profit of the industry and $I=\sum_{i=1}^{m} I_{i}$ is total investment in abatement technology. The lobby of the industry chooses the contribution $C_{E}$ to maximize net of contributions industry welfare: $\max _{C_{E}} \Pi(p)-I-C_{E}(p)$. The gross of contributions welfare of the owners of carbon securities is the value of the securities in the second period minus the amount they had to pay to purchase the securities in the first period:

$$
W_{B}(p, I)=-p \frac{\partial \Pi}{\partial p}-\xi n
$$

where $\xi$ is the price that the government sold an security for and $n$ is the total number of securities. ${ }^{4}$ The revenue of the owners of the securities, $-p \frac{\partial \Pi}{\partial p}=$ $-p \Pi^{\prime}(p)$, is the product of the carbon price and the emission quota. A carbon security holder prefers a carbon price that maximizes $-p \Pi^{\prime}(p)$.

As for the lobby of the carbon-using industry, it is assumed that the owners of the carbon securities are able to organize themselves into a lobby group in order to influence the political process. The lobby of the owners of carbon securities does not face any borrowing constraints when they make campaign contributions.

Finally, consider the investment stage. Suppose that each firm $i$ believes itself too small to have any meaningful impact on the carbon price $p$ or the aggregate investment level $I$. No industry-wide coordination is possible on investment. The motivation for this assumption is that it is fairly easy for the other firms to observe if a firm contributes to the lobby, but it is much harder to observe how much a firm

\footnotetext{
${ }^{4}$ The sale of the carbon securities is not explicitly modeled here. Conducting an auction has some well known advantages. However, all results of the paper also follow thorough if the carbon securities would be sold at a fixed price (which could be zero).
} 
invests in abatement technology. So free-riding is a more pressing concern when it comes to investment than for lobby contributions.

In period 1, each firm individually chooses an investment level $I_{i}$ which determines its demand for energy in the following period. For given $p, I$ and $\theta$ an individual firm's profit depends on its investment decision:

$$
w_{i}\left(I_{i} ; p, I, \theta\right)=\pi\left(I_{i} ; p\right)-I_{i}-\frac{1}{m} C_{E}(p, \theta, I) .
$$

The carbon price $p$ is an input price. Thus, $\frac{\partial \pi}{\partial p}<0$. An individual firm's demand for energy is $-\frac{\partial \pi}{\partial p}=-\pi^{\prime}$.

If a firm invests, it requires less energy for its production. So for any $p$, $\frac{\partial\left(-\pi^{\prime}\right)}{\partial I}<0$. In other words, for a given carbon price, a firm's demand for energy decreases with the investment level.

An important question is who would buy the carbon securities when the government sells them in the first period. The effectiveness of carbon securities as a policy tool depends on the allocation of the carbon securities in the second period. There is an incentive to form a lobby in favor of maximizing the value of the securities unless the carbon securities are all held by carbon using firms and each firm's proportion of carbon securities is the same as the firm's share of future carbon emissions. The benefits of carbon securities increase with the fraction of the securities is held for investment purposes (resale) and not for a firm's own carbon consumption. This paper first focuses for ease of exposition on the benchmark case in which all securities are held by outsiders to the carbon-using industries and then discusses what happens if this is not the case.

Environmental interest groups like Greenpeace, the Sierra Club and Earthwatch are not included in the model. There are two reason for this: First, the size of the budget of environmental interest groups is significantly smaller than the contributions made by major carbon-using industries. Second, it seems likely that the attention of environmental interest groups would shift from global warming to other environmental issues once a system with carbon securities led to a carbon price close to the social optimum.

\section{A Carbon Tax}

\subsection{The Equilibrium}

Suppose a carbon tax is the policy instrument. The two period game can be solved by backward induction. First, the menu auction stage in which $p$ is determined has 
to be considered. In a second step, the individual firm's investment decision can be analyzed. The investment decision depends on the expected carbon price and potentially on the variance of the carbon price.

The lobby offers a contribution function, which specifies a financial contribution depending on the government's choice of the carbon price. Thus, the game is a menu auction (Bernheim and Whinston (1986)).

Definition 1. An equilibrium of the tax game is a contribution function $C_{E}(p, \theta, I)$, a set of individual firm investment levels $\left(I_{1}, \ldots I_{m}\right)$ and a carbon price p such that

a) for each firm $i, I_{i} \in \Im$ maximizes the expected net of contributions welfare of the firm given the expected equilibrium contribution schedules and carbon price

b) $C_{E}(p, \theta, I)$ and $p$ are an equilibrium of the menu auction stage of the carbon securities game; that is

(i) the contribution function maximizes the joint welfare of the lobby's members given the carbon price $p$

(ii) carbon price p maximizes the government's objective taking the contribution function as given

The following proposition states the necessary and sufficient conditions for an equilibrium of the menu auction stage of the tax game.

Proposition 1. Given the aggregate investment level $I,\left(C_{E}^{0}, p_{T}\right)$ is an equilibrium of the menu auction stage if and only if

a) $C_{E}^{0}$ is feasible

b) $p_{T}$ maximizes $C_{E}(p ; \theta, I)-\theta G(p ; I)$

c) $p_{T}$ maximizes $W_{E}(p ; \theta, I)-\theta G(p ; I)$

d) there exists a $p^{E}$ that maximizes $W_{G}(p ; \theta, I)$ such that $C_{E}^{0}\left(p^{E}\right)=0$

The first condition of the proposition is a standard feasibility condition. The second condition requires that the carbon price is optimal for the government since $C_{E}(p ; \theta, I)-a G(p ; I)$ is the government revenue after contributions have been received. The third and fourth conditions together state that the lobby's contribution schedule has be optimal. 
In general, there are a large number of equilibria in menu auctions. However, only equilibria supported by so-called truthful contribution schedules are stable to non-binding communication among players. Also, the best response set to any strategy played by an opponent includes a truthful strategy (Bernheim and Whinston (1986)). Therefore, I focus in the following on equilibria supported by truthful contribution schedules.

Definition 2. A truthful contribution schedule takes the form $C_{i}\left(p ; \theta, I, B_{i}\right)=$ $\max \left[0, W_{i}-B_{i}\right]$ where $B_{i}$ is a constant.

Corollary 1. Suppose the contribution schedule is truthful. There is a unique equilibrium. The equilibrium carbon price $p_{T}$ satisfies $\theta G^{\prime}(p ; I)=\Pi^{\prime}(p ; I)$.

Proposition 2. The carbon price under a tax system is lower than the socially optimal price: $p_{T}<p^{*}$.

Most current research suggests that the optimal carbon price is between $\$ 30$ (Nordhaus (2010)) and \$85 (Stern (2007)) per ton. The current actual carbon price is approximately $\$ 5$.

In the absence of lobbying the government would choose the level of carbon abatement that maximizes social welfare. However, with lobbying in favor of no or minimal carbon abatement, the carbon price set by the government is below the socially optimal price. Since investment is positively correlated with the expected carbon price, the equilibrium investment level, $I^{T}$, is below the investment level at the optimal carbon price, $I^{*}$.

\subsection{Effect of Uncertainty}

In period 1, there may be significant uncertainty about the state of the world in period 2. This can take the form of either climate uncertainty (how costly global warming is) or political uncertainty (what party will be in charge). This section shows how both types of uncertainty can be considered within the framework of the model. The goal is to study uncertainty while keeping the model as simple as possible. The following shows that the variance of $\theta$ can be interpreted as either political uncertainty or climate uncertainty.

First consider political uncertainty: a situation in which in period 1 it is unknown which party will be in charge of choosing the carbon price once time 2 is reached. Suppose there are at least two parties and these parties differ in how important it is for them that the carbon price is close to $p^{*}$ or they may place different 


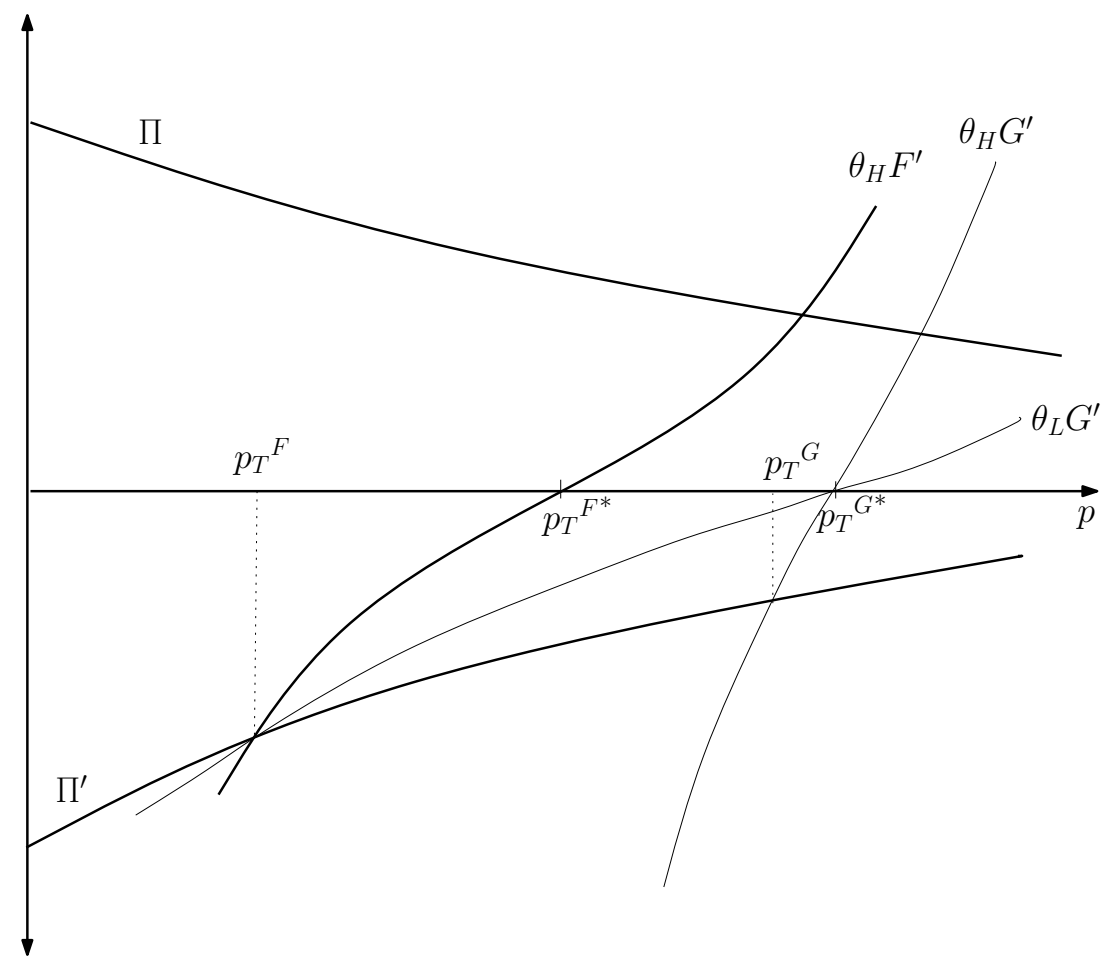

Figure 1: The effect of uncertainty

weights on campaign contributions relative to voter welfare. The ex ante (period 1) variance of period 2's carbon price depends on the distribution of $\theta$.

Next, assume that there is no political uncertainty (all politicians have an $\theta$ equal to $\theta_{H}$ ) but there is considerable uncertainty about the climate. The social cost of carbon function can either be $G$ or $F$ and this uncertainty is not resolved until period 2 is reached. The state of the world characterized by social cost of carbon function $G$ can be thought of as a state with high climate sensitivity and global warming imposing significant cost to society. The state of the world characterized by social cost of carbon function $F$ can be interpreted as a state with either low climate sensitivity, efficient geoengineering options or low cost of global warming. If the social cost of carbon function is $G$ then the socially optimal carbon price is $p_{G}^{*}$ and any downward deviations are expensive. Hence $G^{\prime}$ is steep (see Figure 1). If the social cost of carbon function is $F$ then the socially optimal carbon price is $p_{F}^{*}$ and any downward deviations are less expensive than under $G$. 
As Figure 1 shows, the same equilibrium as under $F$ can be found by using $G$ and choosing the appropriate $\theta$, here $\theta_{L}$. Therefore, to keep things as simple as possible both climate uncertainty and political uncertainty is in the following studied by varying $\theta$.

\subsection{A Comparison to a Permit System}

Most of the literature considers carbon tax systems and cap and trade systems as policy instruments with significant differences and correspondingly different advantages and disadvantages. Within the model considered here both instruments have more similarities than differences. Hence it is useful to consider them together. The two policy instruments are essentially equivalent here since (i) there is no demand uncertainty within a period, (ii) both under the tax and the cap and trade system, the policy is set at the beginning of period 2 and (iii) there is no banking of permits since there is only one period in which permits are required. So it does not make a difference whether the carbon price is chosen by the government or whether an emission quantity is chosen. Both lead to the same equilibrium. ${ }^{5}$

\section{Carbon Securities}

Compared to other carbon abatement policy instruments, the key feature of system with carbon securities is that the amount of carbon emissions allowed per security is determined after the security has been sold. Each of the $n$ carbon securities gives its owner the right to emit up to $\frac{1}{n}$ of the society's total desired carbon emissions for year $2, X$. This amount $X$ is unknown to potential buyers at time 1 when they have to decide whether they want to purchase a security or not. Once all securities have been sold, firms choose their level of investment in energy-saving technology technology. In period 2 the political process determines $X$, taking into account the voters' preferences, the aggregate investment level and any contributions from lobbies representing either the interests of the carbon-using industry or the owners of carbon securities.

\footnotetext{
${ }^{5}$ The assumption that there is no demand uncertainty within a period, is more realistic for short periods than for long periods. The model could be extended to the case of demand uncertainty. However, demand uncertainty affects both a cap and trade system and the here proposed system equally, so for the purpose of comparing an existing mechanism to a new mechanism, very little is gained by including demand uncertainty.
} 
The securities game is a common agency game with two principals, the lobbies of the carbon-using industry and the holders of carbon securities, and one agent, the government, who has the discretionary power of selecting the carbon price. Lobbyists compete by simultaneously offering contribution schedules conditional on the policy ultimately selected. The government chooses the carbon price which maximizes its welfare, which depends on the weighted sum of campaign contributions and social welfare.

As in the previous section on the tax game, there are essentially two periods. In the first period the following actions and events take place: The government sells $n$ securities. The owners of the securities form a lobby and the carbonusing industry forms a lobby. Each firm in the carbon-using industry chooses its investment level. In the second period, the lobbies find out how much the government is influenced by campaign contributions. The lobbies then offer their contribution schedules. The government chooses an amount of desired maximum carbon emissions $X$ and thereby determines the price of carbon $p$. Each security owner sells $\frac{X}{n}$ carbon allowances to firms in the carbon-using industry at a price of $p$ per unit of carbon.

The government has similar preferences as in the previous section. The only addition is that the government now receives campaign contributions not just from the lobby of the carbon-using industry but from the lobby representing the interests of the carbon securities holders.

\subsection{The Equilibrium of the Carbon Securities Game}

The fundamental difference between the carbon securities game and the tax game is that in the former there is political competition while in the later there is not. In the carbon securities game there are two active lobbies, while in the tax game only the lobby of the carbon-using industry is active. Political competition has a strong effect on the equilibrium carbon price and campaign contributions.

Definition 3. An equilibrium of the carbon securities game is a set of contribution functions $\left\{C_{E}(p ; \theta, I), C_{B}(p ; \theta, I)\right\}$, an investment level $I$ and a carbon price $p$ such that

a) I maximizes the expected net of contributions welfare of the carbon-using industry given the expected equilibrium contribution schedules and carbon price

b) $\left\{C_{E}(p ; \theta, I), C_{B}(p ; \theta, I)\right\}$ and $p$ are an equilibrium of the menu auction stage of the carbon securities game; that is 
(i) each contribution function maximizes the joint welfare of the group's members given the carbon price and the other groups contribution function

(ii) carbon price p maximizes the government's objective taking the contribution function as given

Proposition 3. Given the investment level $I,\left(C_{B}^{*}, C_{E}^{*}, p_{S}\right)$ is an equilibrium of the menu auction stage if and only if

a) $C_{E}^{*}, C_{B}^{*}$ are feasible

b) $p_{S}$ maximizes $C_{B}(p ; \theta, I)+C_{E}(p ; \theta, I)-\theta G(p, I)$

c) $p_{S}$ maximizes $W_{B}(p ; \theta, I)-\theta G(p ; I)+C_{E}(p ; \theta, I)$

d) there exists a $p^{B}$ that maximizes $W_{G}(p ; \theta, I)$ such that $C_{B}^{*}\left(p^{B}\right)=0$

e) $p_{S}$ maximizes $W_{E}(p ; \theta, I)-\theta G(p ; I)+C_{B}(p ; \theta, I)$

f) there exists a $p^{E}$ that maximizes $W_{G}(p ; \theta, I)$ such that $C_{E}^{*}\left(p^{E}\right)=0$

This proposition extends Proposition 1 by adding an optimality condition for the lobby of the owners of carbon securities.

Corollary 2. Suppose contribution schedules are truthful. There is a unique equilibrium. The equilibrium carbon price $p_{S}$ satisfies $\theta G^{\prime}(p ; I)=-p \Pi^{\prime \prime}(p ; I)$.

\subsection{Comparison with a tax or permit system}

With a permit system or a carbon tax, only the carbon-using industry has a strong financial incentive to lobby for a carbon price in its favor. Introducing property rights for emissions creates a counterbalancing force: now there is a group that has a strong financial interest in lobbying for a high carbon price. Hence, the equilibrium carbon price is higher. However, under both system the carbon price is below the social optimum.

If firms' investment in the first period is unaffected by this switch of policy instruments, then the new equilibrium with carbon securities is at the intersection of the dashed line and the $\theta G_{T}^{\prime}$ line (Figure 2). Note that $-p \Pi^{\prime \prime}>\Pi^{\prime}$ if demand 


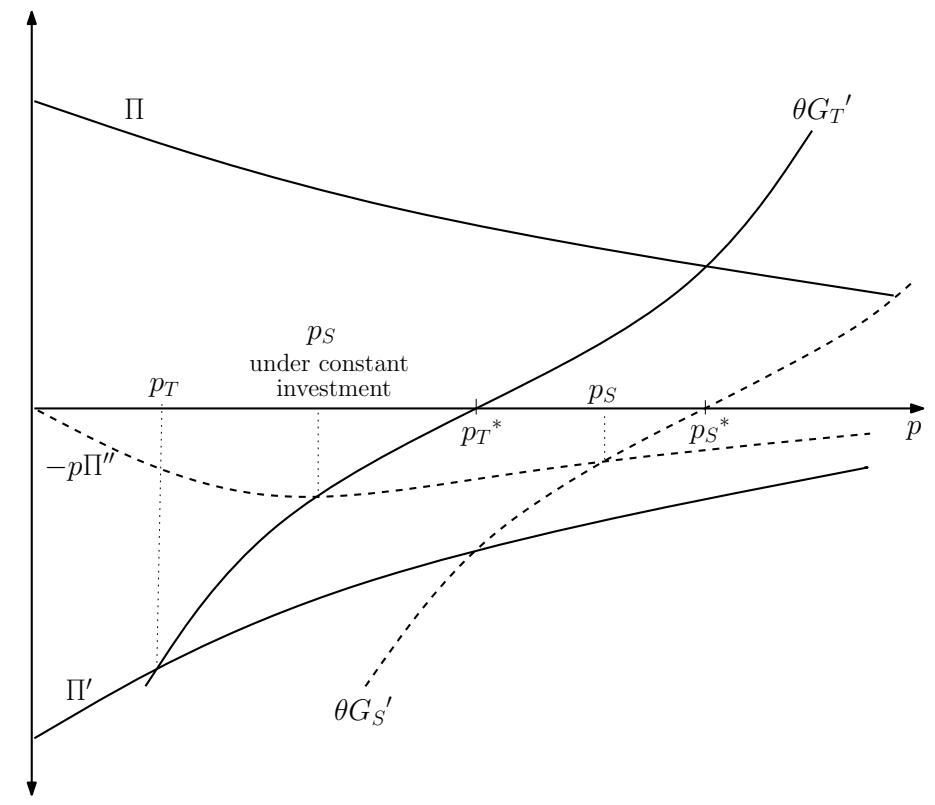

Figure 2: The equilibrium with carbon securities.

for carbon is inelastic which will be assumed in the following. ${ }^{6}$ With carbon securities, increasing the carbon price is more attractive for the government since it leads to a higher campaign contributions from the lobby of the carbon security holders.

As forward looking actors, firms anticipate in period 1 that there switch from a carbon tax to carbon securities implies that carbon emissions in the second period will be more expensive. Therefore, they will invest more in carbon abatement technology in the first period. This increase in first period investment affects both the $\theta G^{\prime}$ line and the $-p \Pi^{\prime \prime}$ line. The $\theta G^{\prime}$ shifts to the right and the $-p \Pi^{\prime \prime}$ line shifts upwards in response to an increase in aggregate investment $I$. The equilibrium carbon price with carbon securities is $p_{S}$.

If there is no effect on investment, the carbon price increases to ' $p_{S}$ under constant investment.' However, since there is now a higher equilibrium carbon price and investment is more attractive under a higher carbon price, there is higher equilibrium investment. Assume in the following that a high economy-wide level of investment in abatement technology makes it attractive to set tight emission

\footnotetext{
${ }^{6}$ Numerous empirical studies show that demand for carbon based energy sources is typically inelastic. See for example Cooper (2003).
} 
target and that deviations from the optimal carbon price are no more desirable than at lower investment levels. ${ }^{7}$ The new socially optimal carbon price is $p_{S}{ }^{*}$. The equilibrium carbon price under the increased investment level is $p_{S}$.

Proposition 4. While the carbon price under either system is below the social optimum, $p_{T}<p^{*}\left(I^{T}\right)$ and $p_{S} \leq p^{*}\left(I^{S}\right)$, in the carbon securities game the carbon price is higher than in the tax game: $p_{T}<p_{S}$.

Thus, the carbon price is higher in the carbon securities game for two reasons. First, there is the lobbying effect. Having political competition over the carbon price mitigates the effect of the lobby of the carbon-using industry. Second, there is an investment effect. A change in the equilibrium price affects investment in energy saving technology. This change in the investment level has an effect on the socially optimal carbon price and therefore also on the equilibrium carbon price. The size of the effect depends on how sensitive investment is to carbon price changes, how much the socially optimal carbon price depends on investment and on the industry profit function (how easy it is to substitute away from energy sources that require carbon allowances). How close the equilibrium carbon price with carbon securities is to $p^{*}$ depends on the industry profit function as the follow example shows.

Example 1. Consider the case of a linear profit function. This is the situation in which investment is essentially equivalent to gaining access to a specific blueprint for production technology and this technology requires a constant amount of carbon based energy per unit of output. If $\Pi$ is linear then $\Pi^{\prime \prime}$ and $\Pi^{\prime \prime \prime}$ are equal to zero. Therefore, $p_{S}=p^{*}$ and $\frac{d p_{S}}{d \theta}=0$. However,

$$
\frac{d p_{T}}{d \theta}>0
$$

So as expected, the tax equilibrium price increases with $\theta$ : With a high $\theta$, the government puts more weight on social welfare and the tax equilibrium price is higher.

A significant advantage of carbon securities is that they make environmental policy more predictable. To see this consider a two party system, one with a high

\footnotetext{
${ }^{7}$ The motivation for the assumption is the observation that in countries with low levels of investment in abatement technology, the price of carbon emission is lower than in countries with high levels of investment in abatement technology. The second part of the assumption states that curves $\theta G_{T}^{\prime}$ and $\theta G_{P}^{\prime}$ in Figure 2 do not cross.
} 
$\theta$ and one with a low $\theta$ and suppose that there are elections between period 1 and 2 . If the party with the high $\theta$ is elected, then irrespective of the policy instrument, the abatement level will be close to $p^{*}$. If the party with the high $\theta$ is elected, then with a carbon tax a carbon price significantly below $p^{*}$ may be chosen but with carbon securities the carbon price will be fairly close to $p^{*}$. So with a carbon tax, there is significant uncertainty what the carbon price will be. With carbon securities both parties choose a similar carbon price, albeit for different reasons.

The question how early (period 1) investment in energy-saving technology is affected by the choice of the policy instrument is consequently best approached from the perspective of the investment under uncertainty literature (Dixit and Pindyck (1994)). Switching from a tax system to carbon securities affects both the level of the carbon price and the variance of the carbon price. The increase in the expected carbon price makes investment in alternative energy more attractive. The reduction in the variance of the carbon price also encourages investment if the investment is (partially) irreversible. Intuitively, investment in abatement technology is attractive if the carbon price is high but not if it is low. By waiting until uncertainty is resolved a firm avoids making the costly mistake of having invested but the state of the world turning out to be a low socially optimal carbon price (global warming not a serious problem). A decrease of the uncertainty over the future returns from investment, reduces the value of waiting and therefore makes investment in period 1 more attractive. So $I^{T}<I^{S}$.

Also, in the carbon securities game the expected level of global warming is lower than in the tax game due to two effects: First, the carbon price in the carbon securities game is higher because it is closer to the socially optimal carbon price. Second, the socially optimal carbon price in the carbon securities game is higher because there is more investment in energy saving technology. Both effects leads to less global warming in the case of the securities game.

Next, consider government revenue under both the system with carbon securities and under a tax or permit system. Both a permit system and a carbon securities system can be designed so that there is government revenue from selling or auctioning permits or securities. If permits or securities are auctioned off, the revenue is equal in size to that of a tax that generates the same amount of emissions. If demand for carbon is inelastic, Proposition 4 implies that government revenue is larger under the here proposed policy instrument than under traditional alternatives.

Finally, consider the effect of the policy instrument choice on total campaign contributions. Grossman and Helpman (1994) show that if a lobby faces no opposition from competing interests it is able to extract all surplus from its political 
relationship with the government. This implies that contributions of the carbonusing industry in the tax game are equal to the difference of the social cost of carbon function under the tax game equilibrium price and the social cost of carbon function under the socially optimal price. If there are two active lobbies as in the carbon securities game, the government captures all of the surplus from the political relationships.

\subsection{The Performance of Carbon Securities When Some Carbon- Using Firms Purchase Carbon Securities}

Carbon securities are financial assets with an uncertain future value. The future value of carbon securities is affected by climate uncertainty, political uncertainty and uncertainty about the demand for fossil fuels. It seems therefore plausible to anticipate that a large share of securities is bought by investment banks and other entities specialized on investment in assets with uncertain returns. Also, acquiring information about the $\mathrm{CO}_{2}$ market and hiring experts to make forecasts of $\mathrm{CO}_{2}$ prices is costly. Therefore, there are likely significant economies of scale which favor investment banks. ${ }^{8}$

The may be some concerns that carbon securities could be purchased to prevent the formation of a counterlobby by for instance the lobby of carbon using firms. If this lobby buys all securities it can prevent the formation of a lobby of carbon securities holders. As outlined above there are reasons why an average carbon using firm is unlikely to be interested in purchasing carbon securities. So any plan involving a purchase of all carbon securities by the carbon using firms has to overcome a significant free-rider problem. A firm in the carbon using industries prefers that other firms in the industry purchase all securities but would rather not purchase any securities itself. It seems very unlikely that the lobby of carbon using firms would be able to monitor if their members choose to purchase an appropriate amount of carbon securities. This is much more difficult to monitor than if firms pay their lobby contributions.

In addition, politicians have a strong incentive to set in place laws prohibiting insider ownership since they benefits from the presence of an additional interest group. With an addition interest group representing people who bought carbon securities for investment purposes, politicians receive higher campaign contributions and the equilibrium policy level is closer to the social optimum and should

\footnotetext{
${ }^{8}$ While there may be some large firms affected by abatement policy with sufficient economies of scale to hire experts, a large number of firm affected are small and medium size firms.
} 
hence appeal more to the electorate.

If an outsider to the carbon using industry owns a carbon security, this investor prefers a carbon price that maximizes the value of the carbon securities, $-p \Pi^{\prime}(p)$. This changes if a carbon security is held by an insider to the carbon-using industry. An insider owns carbon securities for his own consumption of carbon allowances and possibly in addition to that in order to sell any left over carbon allowances to other firms. The insider prefers an emission quota high enough so that her own carbon emissions are covered by her carbon allowances. However, there is hardly any profit realized from selling any left over allowances if the price is very low. Hence, a carbon price of zero is not profit maximizing for a carbon using firm that owns carbon allowances. ${ }^{9}$

Suppose that of the $m$ identical firms in the industry a fraction $\alpha$ holds the $n$ securities and that each of these $\alpha m$ firms holds the same share of the carbon securities. The remaining firms have to purchase emissions coupons after the menu auction stage from these $\alpha m$ firms.

The firms belonging to the fraction $\alpha$ are both users of carbon allowances and sellers. As they require allowances themselves, they benefit from a low carbon price, however, since they sell their leftover coupons, a high carbon price can be of advantage to them.

Proposition 5. The equilibrium price with some securities held by insiders lies between the carbon securities equilibrium price with $100 \%$ outsider ownership and the tax equilibrium price: $p_{T}<p_{\alpha S}<p_{S}$.

Figure 3 illustrates the equilibrium if some of the carbon securities are held by carbon-using firms. The line $\alpha \Pi^{\prime}(p)-(1-\alpha) p \Pi^{\prime \prime}(p)$ shows the marginal campaign contributions as a function of the carbon price.

A system based on carbon securities performs better with respect to equilibrium carbon price, variance of the carbon price and investment level than a system based on either a carbon tax or carbon permits if at least one of the carbon using firm does not purchases a share of carbon securities that is equal to its share of carbon emission. A carbon securities system performs as well as a tax or permit system if every carbon using firm purchases a share of carbon securities that is equal to its share of future carbon emission.

In practice this means that unless the unlikely event that all securities are bought by carbon-using firms and each firm purchases a fraction of carbon securities that exactly equals its share of future total emissions, carbon securities

\footnotetext{
${ }^{9}$ Carbon-using firms that do not purchase carbon securities prefer a carbon price equal to zero.
} 


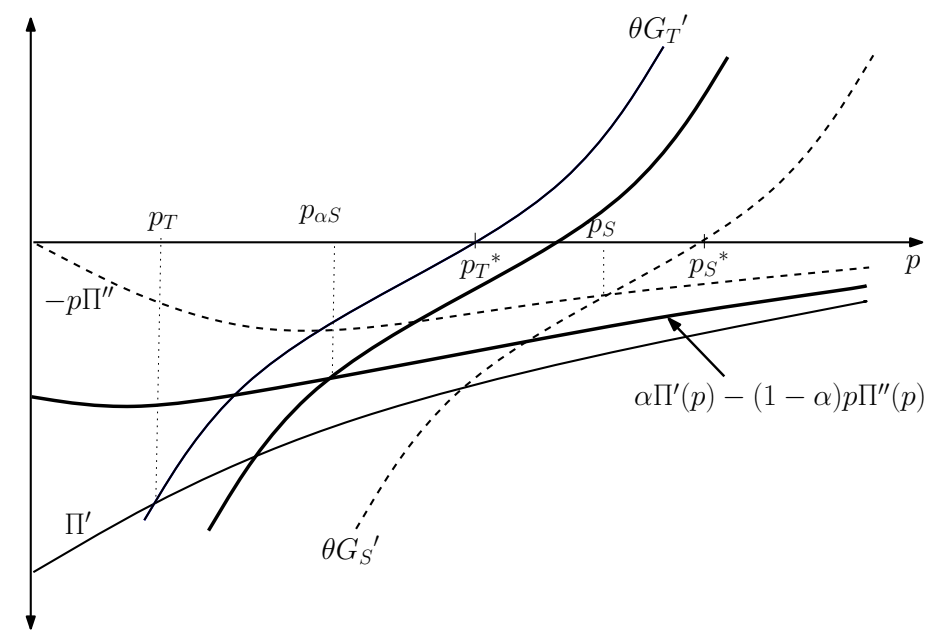

Figure 3: The range of equilibrium carbon prices if some carbon-using firms purchase carbon securities.

perform better - both with respect to the level of the equilibrium price and with respect to the variance of the equilibrium price - than a carbon tax system or a carbon permit system.

This superperfect distribution in which all securities are bought by carbonusing firms and each firm purchases a fraction of carbon securities that exactly equals its share of future total emissions is not just highly unlikely to occur in practice but is also undesirable from the perspective of a politician. The reason is that campaign contributions are lower for security distributions close to the superperfect distribution.

So far this chapter only considered the case that all securities are held by carbon-using firms and the fraction $\alpha$ specified how many of the firms own securities and how many do not. It is of course also conceivable that some securities are held by carbon using firms and some securities are held by outsiders to the carbon-using industry. However, this case is analytically equivalent to the case discussed above. It makes no difference if a carbon using firm purchases a security for investment purposes or if an outside investor purchases the carbon security for investment purposes. All that matters is what fraction of securities is held for investment purposes or in other words held with the intend to sell allowances. 


\section{Conclusion}

In a perfect world there would be no lobbies motivated by self interest since the policy makers is not influenced by campaign contributions but only by social welfare considerations. This paper showed that in a less than perfect world carbon securities have significant advantages over existing policy instruments.

One issue that has not yet been to addressed is the potentially large opposition against the initial introduction of carbon securities. This is a legitimate concern and it may take a one time political will to introduce the system, thing that carbon securities have going for them is that they are a very attractive policy instrument from a politician's point of view.

\section{References}

Aidt, Toke S., "Political internalization of economic externalities and environmental policy," Journal of Public Economics, July 1998, 69 (1), 1-16.

Baumol, William J. and Wallace E. Oates, The Theory of Environmental Policy, Cambridge University Press, 1988.

Bernheim, B. Douglas and Michael D. Whinston, "Menu Auctions, Resource Allocation, and Economic Influence," The Quarterly Journal of Economics, 1986, 101 (1), 1-31.

Cooper, John C.B., "Price elasticity of demand for crude oil: estimates for 23 countries," OPEC Review, 2003, 27, 1-8.

Dixit, Avinash K. and Robert S. Pindyck, Investment under Uncertainty, Princeton University Press, Princeton, New Jersey, 1994.

Ekins, Paul and Stefan Speck, "Competitiveness and Exemptions From Environmental Taxes in Europe," Environmental and Resource Economics, 1999, 13, 369-396. 10.1023/A:1008230026880.

Grossman, Gene M. and Elhanan Helpman, "Protection for Sale," The American Economic Review, 1994, 84 (4), 833-850.

Keller, Klaus, Alexander Robinson, David F. Bradford, and Michael Oppenheimer, "The regrets of procrastination in climate policy," Environmental Research Letters, 2007. 
Keohane, Nathaniel O., Richard L. Revesz, and Robert N. Stavins, "The Choice of Regulatory Instruments in Environmental Policy," Harvard Environmental Law Review, 2002, 22, 313-367.

Markussen, Peter and Gert Tinggaard Svendsen, "Industry lobbying and the political economy of GHG trade in the European Union," Energy Policy, 2005, $33(2), 245-255$.

McKibbin, Warwick J. and Peter J. Wilcoxen, "The Role of Economics in Climate Change Policy," The Journal of Economic Perspectives, 2002, 16 (2), 107129.

Metcalf, Gilbert E., "Designing a Carbon Tax to Reduce U.S. Greenhouse Gas Emissions," Rev Environ Econ Policy, 2009, 3 (1), 63-83.

Murray, Brian C., Richard G. Newell, and William A. Pizer, "Balancing Cost and Emissions Certainty: An Allowance Reserve for Cap-and-Trade," Review of Environmental Economics and Policy, 2009, 3 (1), 84-103.

Nordhaus, William D., "Economic aspects of global warming in a postCopenhagen environment," Proceedings of the National Academy of Sciences, 2010, 107 (26), 11721-11726.

Oates, Wallace E. and Paul R. Portney, "The political economy of environmental policy," in K. G. Mler and J. R. Vincent, eds., Handbook of Environmental Economics, Vol. 1 of Handbook of Environmental Economics, Elsevier, 03 2003, chapter 8 , pp. 325-354.

Stavins, Robert N., The Political Economy of Environmental Regulation, Elgar, Edward Publishing, 2004.

Stern, Nicholas, The Economics of Climate Change: The Stern Review, Cambridge University Press, January 2007.

Webster, Mort, Ian Sue Wing, and Lisa Jakobovits, "Second-best instruments for near-term climate policy: Intensity targets vs. the safety valve," Journal of Environmental Economics and Management, 2010, 59 (3), 250 - 259. 


\section{A Mathematical Appendix}

Proof of Proposition 1. The proposition follows immediately from Lemma 2 of Bernheim and Whinston (1986).

Proof of Corollary 1. First, consider uniqueness. When the contribution schedule is truthful, condition (b) of Proposition 1 simplifies to

$$
W_{E}(p, I)-B_{E}-\theta G(p, I)
$$

where $B_{E}$ is a constant. Therefore, conditions (b) and (c) of Proposition 1 lead to the same first order condition. Second, to see that the equilibrium carbon price $p_{T}$ satisfies $\theta G^{\prime}(p, I)=\Pi^{\prime}(p, I)$ start with either condition (b) and (c) of Proposition 1 and replace $W_{E}$ with the expression in Equation 4. This yields

$$
\Pi(p, I)-I-B_{E}-\theta G(p, I)
$$

Therefore, the FOC characterizing the equilibrium of the tax game is $\theta G^{\prime}(p, I)=$ $\Pi^{\prime}(p, I)$.

Proof of Proposition 2. Since $p$ is an input price $\Pi$ is a decreasing function of $p$ : $\Pi^{\prime}<0$. This implies that the tax game equilibrium price, $p_{T}$, has to be in the range of $p$ in which it holds that $\theta G^{\prime}(p, I)<0$. Since $G$ by assumption has a unique minimum, $p^{*}$, it follows that $\theta G^{\prime}(p, I)<0$ for all $p<p^{*}$. Therefore, $p_{T}<p^{*}$.

Proof of Proposition 3. Similarly to Proposition 1, the result follows from Lemma 2 of Bernheim and Whinston (1986).

Proof of Corollary 2. Uniqueness under truthful strategies follows directly from Propositions 3 and the definition of truthful strategy:

$$
C_{B}(p, \theta, I)=W_{B}(p)-B_{B}
$$

and

$$
C_{E}(p, \theta, I)=W_{E}(p)-B_{E}
$$

Therefore, conditions (b), (c) and (e) lead to the same first order condition when strategies are truthful. Substituting the relevant terms, $p$ maximizes

$$
-p \Pi^{\prime}(p)-\xi n-\theta G(p)+\Pi(p)-I-B_{E}
$$

where $I, B_{E}, \xi$ and $n$ do not depend (in the menu auction stage) on the choice of $p$. Therefore, the first order condition that characterizes the equilibrium of the carbon securities is $\theta G^{\prime}(p ; I)=-p \Pi^{\prime \prime}(p ; I)$. 
Proof of Proposition 4. Similar to Proposition 2. It follows from the properties of the $G$ function and of demand being inelastic that $p_{T}<p_{S}$.

Proof of Proposition 5. As before, consider a common agency game. The two groups of firms have different interest, therefore it makes sense for them to form separate lobbies. Each lobby attempts to affect the carbon price in their favor. Their gross of contributions payoff of the $(1-\alpha) m$ firms that did not purchase any carbon securities is

$$
W_{E(1-\alpha)}\left(p ; I_{\alpha}, I_{1-\alpha}\right)=(1-\alpha) \Pi\left(p ; I_{\alpha}, I_{1-\alpha}\right)-I_{1-\alpha}
$$

and the gross of contributions payoff of the $\alpha m$ firms that did purchase carbon securities is

$$
W_{E \alpha}\left(p ; I_{\alpha}, I_{1-\alpha}\right)=\alpha \Pi\left(p ; I_{\alpha}, I_{1-\alpha}\right)-I_{\alpha}-(1-\alpha) p \Pi^{\prime}\left(p ; I_{\alpha}, I_{1-\alpha}\right)-\xi n
$$

where $I_{\alpha}$ and $I_{1-\alpha}$ are the respective aggregate investment levels.

The government maximizes the weighted sum of campaign contributions and voters' welfare. $W_{G}$ denotes the welfare of the government:

$$
W_{G}\left(p ; \theta, I_{\alpha}, I_{1-\alpha}\right)=C_{E(1-\alpha)}\left(p ; I_{\alpha}, I_{1-\alpha}\right)+C_{E \alpha}\left(p ; I_{\alpha}, I_{1-\alpha}\right)-\theta G\left(p ; I_{\alpha}, I_{1-\alpha}\right)
$$

The first order condition describing the equilibrium if a fraction $\alpha$ of the firms in the carbon-using industry holds the $n$ securities is

$$
\alpha \Pi^{\prime}(p)-(1-\alpha) p \Pi^{\prime \prime}(p)-\theta G^{\prime}(p)=0 .
$$

Recall from Corollaries 1 and 2 that the equilibrium condition characterizing the first order condition of the tax game (equivalent to $\alpha=1$ ) is

$$
\Pi^{\prime}(p ; I)-\theta G^{\prime}(p ; I)=0
$$

and the first order condition of the carbon securities game $(\alpha=0)$ is

$$
-p \Pi^{\prime \prime}(p ; I)-a G^{\prime}(p ; I)=0 .
$$

Therefore the equilibrium price in the case considered here, $p_{\alpha S}$, satisfies $p_{T}<$ $p_{\alpha S}<p_{S}$ 
Department of Economics:

Skriftserie/Working Paper:

2009:

WP 09-1 Tomi Kyyrä, Pierpaolo Parrotta and Michael Rosholm: The Effect of Receiving Supplementary UI Benefits on Unemployment Duration ISBN 9788778824035 (print); ISBN 9788778824042 (online)

WP 09-2 Dario Pozzoli and Marco Ranzani: Old European Couples' Retirement Decisions: the Role of Love and Money ISBN 9788778824165 (print); ISBN 9788778824172 (online)

WP 09-3 Michael Gibbs, Mikel Tapia and Frederic Warzynski: Globalization, Superstars, and the Importance of Reputation: Theory \& Evidence from the Wine Industry ISBN 9788778824189 (print); ISBN 9788778824196 (online)

WP 09-4 Jan De Loecker and Frederic Warzynski: Markups and FirmLevel Export Status ISBN 9788778824202 (print); ISBN 9788778824219 (online)

WP 09-5 Tor Eriksson, Mariola Pytliková and Frédéric Warzynski: Increased Sorting and Wage Inequality in the Czech Republic: New Evidence Using Linked Employer-Employee Dataset ISBN 9788778824226 (print); ISBN 9788778824233 (online)

WP 09-6 Longhwa Chen and Tor Eriksson: Vacancy Duration, Wage Offers, and Job Requirements - Pre-Match Data Evidence ISBN 9788778824240 (print); ISBN 9788778824257 (online)

WP 09-7 Tor Eriksson, Valérie Smeets and Frédéric Warzynski: Small Open Economy Firms in International Trade: Evidence from Danish Transactions-Level Data ISBN 9788778823861 (print); ISBN 9788778823878 (online)

WP 09-8 Dario Pozzoli and Marco Ranzani: Participation and Sector Selection in Nicaragua ISBN 9788778823885 (print); ISBN 9788778823892 (online) 
WP 09-9 Rikke Ibsen, Frederic Warzynski and Niels Westergård-Nielsen: Employment Growth and International Trade: A Small Open Economy Perspective ISBN 9788778823908 (print); ISBN 9788778823915 (online)

WP 09-10 Roger Bandick and Holger Görg: Foreign acquisition, plant survival, and employment growth ISBN 9788778823922 (print); ISBN 9788778823939 (online)

WP 09-11 Pierpaolo Parrotta and Dario Pozzoli: The Effect of Learning by Hiring on Productivity

ISBN 9788778823946 (print); ISBN 9788778823953 (online)

WP 09-12 Takao Kato and Pian Shu

Peer Effects, Social Networks, and Intergroup

Competition in the Workplace

ISBN 9788778823984 (print); ISBN 9788778823991 (online)

WP 09-13 Sanne Hiller and Erdal Yalcin: Switching between Domestic Market Activity, Export and FDI

ISBN 9788778824004 (print); ISBN 9788778824028 (online)

WP 09-14 Tor Eriksson and Mariola Pytlikova: Foreign Ownership Wage Premia in Emerging Economies: Evidence from Czech Republic ISBN 9788778824035 (print); ISBN 9788778824042 (online)

WP 09-15 Astrid Würtz Rasmussen: Family Structure Changes and Children's Health, Behavior, and Educational Outcomes ISBN 9788778824059 (print); ISBN 9788778824066 (online)

WP 09-16 Tor Eriksson: How Many Danish Jobs Can (Potentially) Be Done Elsewhere?

ISBN 9788778824073 (print); ISBN 9788778824080 (online)

WP 09-17 Lorenzo Cappellari, Claudio Lucifora and Dario Pozzoli: Determinants of Grades in Maths for Students in Economics ISBN 9788778824103 (print); ISBN 9788778824110 (online)

WP 09-18 Yingqiang Zhang and Tor Eriksson: Inequality of Opportunity and Income Inequality in Nine Chinese Provinces, 1989-2006 ISBN 9788778824127 (print); ISBN 9788778824134 (online) 
WP 09-19 Ricard Gil and Frederic Warzynski: Vertical Integration, Exclusivity and Game Sales Performance in the U.S. Video Game Industry ISBN 9788778824141 (print); ISBN 9788778824165 (online)

WP 09-20 Christian Gormsen: Intransparent Markets and Intra-Industry Trade ISBN 9788778824172 (print); ISBN 9788778824189 (online)

WP 09-21 Jan Bentzen and Valdemar Smith: Wine production in Denmark Do the characteristics of the vineyards affect the chances for awards?

ISBN 9788778824196 (print); ISBN 9788778824202 (online)

WP 09-22 Astrid Würtz Rasmussen: Allocation of Parental Time and the Long-Term Effect on Children's Education ISBN 9788778824233 (print); ISBN 9788778824240 (online)

2010:

WP 10-01 Marianne Simonsen, Lars Skipper and Niels Skipper:

Price Sensitivity of Demand for Prescription Drugs: Exploiting a Regression Kink Design ISBN 9788778824257 (print); ISBN 9788778824264 (online)

WP 10-02 Olivier Gergaud, Valérie Smeets and Frédéric Warzynski: Stars War in French Gastronomy: Prestige of Restaurants and Chefs'Careers ISBN 9788778824271 (print); ISBN 9788778824288 (online)

WP 10-03 Nabanita Datta Gupta, Mette Deding and Mette Lausten: Medium-term consequences of low birth weight on health and behavioral deficits - is there a catch-up effect? ISBN 9788778824301 (print); ISBN 9788778824318 (online)

WP 10-04 Jørgen Drud Hansen, Hassan Molana, Catia Montagna and Jørgen Ulff-Møller Nielsen: Work Hours, Social Value of Leisure and Globalisation ISBN 9788778824332 (print); ISBN 9788778824349 (online)

WP 10-05 Miriam Wüst: The effect of cigarette and alcohol consumption on birth outcomes ISBN 9788778824455 (print); ISBN 9788778824479 (online) 
WP 10-06 Elke J. Jahn and Michael Rosholm:Looking Beyond the Bridge: How Temporary Agency Employ-ment Affects Labor Market Outcomes ISBN 9788778824486 (print); ISBN 9788778824493 (online)

WP 10-07 Sanne Hiller and Robinson Kruse: Milestones of European Integration: Which matters most for Export Openness? ISBN 9788778824509 (print); ISBN 9788778824516 (online)

WP 10-08 Tor Eriksson and Marie Claire Villeval: Respect as an Incentive ISBN 9788778824523 (print); ISBN 9788778824530 (online)

WP 10-09 Jan Bentzen and Valdemar Smith: Alcohol consumption and liver cirrhosis mortality: New evidence from a panel data analysis for sixteen European countries ISBN 9788778824547 (print); ISBN 9788778824554 (online)

WP 10-10 Ramana Nanda: Entrepreneurship and the Discipline of External Finance ISBN 9788778824561 (print); ISBN 9788778824578 (online)

WP 10-11 Roger Bandick, Holger Görg and Patrik Karpaty: Foreign acquisitions, domestic multinationals, and R\&D ISBN 9788778824585 (print); ISBN 9788778824592 (online)

WP 10-12 Pierpaolo Parrotta, Dario Pozzoli and Mariola Pytlikova: Does Labor Diversity Affect Firm Productivity? ISBN 9788778824608 (print); ISBN 9788778824615 (online)

WP 10-13 Valérie Smeets and Frédéric Warzynski: Learning by Exporting, Importing or Both? Estimating productivity with multi-product firms, pricing heterogeneity and the role of international trade ISBN 9788778824622 (print); ISBN 9788778824646 (online)

WP 10-14 Tor Eriksson and Yingqiang Zhang: The Role of Family Background for Earnings in Rural China ISBN 9788778824653 (print); ISBN 9788778824660 (online)

WP 10-15 Pierpaolo Parrotta, Dario Pozzoli and Mariola Pytlikova: The Nexus between Labor Diversity and Firm's Innovation ISBN 9788778824875 (print); ISBN 9788778824882 (online) 
WP 10-16 Tor Eriksson and Nicolai Kristensen: Wages or Fringes?

Some Evidence on Trade-offs and Sorting

ISBN 9788778824899 (print); ISBN 9788778824905 (online)

WP 10-17 Gustaf Bruze: Male and Female Marriage Returns to Schooling ISBN 9788778824912 (print); ISBN 9788778824929 (online)

WP 10-18 Gustaf Bruze: New Evidence on the Causes of Educational Homogamy

ISBN 9788778824950 (print); ISBN 9788778824967 (online)

WP 10-19 Sarah Polborn: The Political Economy of Carbon Securities and Environmental Policy

ISBN 9788778824974 (print); ISBN 9788778824936 (online) 